\title{
Administração de conflitos existentes no ambiente escolar uma escola estadual do município de Linhares-ES
}

\author{
Management of existing conflicts in the school environment a state school in the city of Linhares-ES \\ Gestión de conflictos existentes en el entorno escolar una escuela pública en la ciudad de Linhares-ES
}

Recebido: 14/12/2021 | Revisado: 19/12/2021 | Aceito: 21/12/2021 | Publicado: 20/12/2021

\author{
Diego Antônio de Souza Pereira \\ ORCID: https://orcid.org/0000-0001-6784-1849 \\ Faculdade Vale do Cricaré, Brasil \\ E-mail: diegoantonio219@hotmail.com
}

\begin{abstract}
Resumo
A revisão da literatura relevante mostra que o conflito é um fenômeno humano essencial e inevitável, porque onde há interação humana, uma probabilidade de gostos e desgostos pessoais. Esses acordos e desacordos entre indivíduos e grupos na escola às vezes levam a conflitos que por sua vez não são construtivos nem perturbadores, mas a forma como são tratados na escola os torna positivos ou negativos. Causas de conflito incluem diferenças de percepção, recursos limitados, autoridade sobreposta entre outras; enquanto as estratégias de gerenciamento de conflitos incluem acomodação, prevenção, competição e colaboração. O objetivo deste artigo que busca analisar a natureza dos conflitos existentes no ambiente escolar e os respectivos impactos, positivos e negativos, dessas divergências para o clima interno e a estrutura pedagógica da escola. Com base nessa discussão, o documento sugere que deve haver reuniões regulares da equipe, boa rede de comunicação e o código de conduta dos professores e alunos deve ser disponibilizado a todos os funcionários e alunos, a fim de conhecerem seus limites para se evitar conflitos.
\end{abstract}

Palavras-chave: Conflito; Escola; Gestão.

\begin{abstract}
A review of the relevant literature shows that conflict is an essential and unavoidable human phenomenon, because where there is human interaction there is a likelihood of personal likes and dislikes. These agreements and disagreements between individuals and groups at school sometimes lead to conflicts which in turn are neither constructive nor disruptive, but the way they are handled at school makes them positive or negative. Causes of conflict include differences in perception, limited resources, overlapping authority, among others; while conflict management strategies include accommodation, prevention, competition and collaboration. The aim of this article, which seeks to analyze the nature of conflicts existing in the school environment and the respective impacts, positive and negative, of these differences on the pedagogical structure of the school. Based on this discussion, the document suggests that there should be regular staff meetings, a good communication network and the code of conduct for teachers and students should be made available to all staff and students, in order to know their limits and avoid conflicts.
\end{abstract}

Keywords: Conflict; School; Management.

\section{Resumen}

Una revisión de la literatura relevante muestra que el conflicto es un fenómeno humano esencial e inevitable, porque donde hay interacción humana existe la probabilidad de gustos y disgustos personales. Estos acuerdos y desacuerdos entre individuos y grupos en la escuela a veces conducen a conflictos que a su vez no son ni constructivos ni disruptivos, pero la forma en que se manejan en la escuela los hace positivos o negativos. Las causas del conflicto incluyen diferencias en la percepción, recursos limitados, superposición de autoridad, entre otras; mientras que las estrategias de manejo de conflictos incluyen acomodación, prevención, competencia y colaboración. El objetivo de este artículo, que busca analizar la naturaleza de los conflictos existentes en el ámbito escolar y los impactos respectivos, positivos y negativos, de estas diferencias sobre el clima interno y la estructura pedagógica de la escuela. Con base en esta discusión, el documento sugiere que debe haber reuniones regulares del personal, una buena red de comunicación y el código de conducta para maestros y estudiantes debe estar disponible para todo el personal y los estudiantes, con el fin de conocer sus límites y evitar conflictos.

Palabras clave: Conflicto; Colegio; Gestión.

\section{Introdução}

As tarefas existentes em um ambiente escolar exigem, na maioria das vezes, grandes esforços que vão desde o aspecto intelectual, emocional até o físico, considerando-se para tal que alguns profissionais permanecem em pé durante a maior parte do 
dia e outros realizam esforços extenuantes como o trabalho docente de se locomover e ficar de pé por horas, as movimentações constantes dos coordenadores, do pessoal da limpeza, coinha e manutenção.

O exercício de quase todos esses profissionais exige destrezas particulares, habilidades e conhecimentos técnicos que variam grandemente quanto à complexidade e as atividades que exercem. Alguns deles exigem, inclusive, que as pessoas os desempenhem utilizando seus conhecimentos científicos, sob intensa pressão emocional, como os professores, por exemplo, onde as remunerações normalmente crescem de forma desporporcional ao trabalho realizado.

É importante analisar o profissional que trabalha na escola, não somente como um fator de serviços prestados de forma ética e educada, mas como um dos componentes mais importantes de qualquer instituição, devendo ser avaliados sob os diferentes enfoques existentes, seja do bem-estar, motivação e disciplina, como os relacionados à solução dos problemas que normalmente ocorrem.

Em suma, deve-se criar o conceito de gerenciamento dos recursos humanos de maneira integral, com a utilização de seus conhecimentos e esforços, mas também os vendo como seres sociais com sentimentos, emoções e necessidades de reconhecimento. Daí a complexidade de se administrar conflitos no ambiente escolar, uma vez que fazem parte de toda e qualquer instituição.

Independente do grau de complexidade que o conflito possa gerar é importante ter em mente que não se trata de um problema com duas soluções quase sempre propostas, onde uma parte tem razão e outra está equivocada. Mas sim de um processo de inconformidade gerado muitas vezes por rivalidades que se chocam por divergências de interesses ou pontos de vista que, mesmo não cruzando os limites da ilegalidade, causam um enorme mal-estar no exercício dos serviços diários prestados pela instituição.

Como justificativa para este trabalho vem a necessidade de se trazer à luz da discussão a questão dos conflitos humanos existentes no ambiente escolar e o desafio de se poder administrá-los de forma eficiente nas instituições escolares e criar um clima organizacional que seja sempre propício à interação entre seus profissionais através do diálogo e harmonia entre os setores que a compõem. Assim, potencializar-se-á não somente a produção de conhecimento, mas se desenvolverá uma postura mais harmonizada e ética, além de condizente com a importância da escola e do que a sociedade espera dela.

Em relação ao percurso metodológico essa pesquisa caracteriza-se por ser uma revisão bibliográfica de cunho qualitativo que culminou em um estudo de caso realizado numa escola estadual do município de Linhares-ES com funcionários pertencentes ao quadro da escola (desde professores, coordenadores, pedagogos, pessoal da limpeza e manutenção), para levantamento de dados na busca por responder ao objetivo deste estudo que vem analisar a natureza dos conflitos existentes no ambiente escolar e os respectivos impactos, positivos e negativos, dessas divergências para o clima interno e a estrutura pedagógica da escola.

\section{Metodologia}

Para este estudo foram consultados artigos com o termo "Administração de conflitos no ambiente escolar", tanto no título como nas palavras chaves nas bases Science Direct e Google Acadêmico. A pesquisa retornou mais de 800 (oitocentas) referências, entre artigos, livros, teses, textos, documentos e dissertações. O foco deste trabalho foram os artigos, devido a qualidade objetiva dos periódicos e congressos.

Para selecionar um conjunto de artigos, como primeiro passo utilizou-se a quantidade de citações dos artigos, filtrando em até 5 citações e posteriormente uma análise da revista e do congresso que são métricas que podem ser aplicadas como critério de qualificação (Conforto et al., 2011).

Regressaram 150 artigos. A partir de buscas com base em descritores, comuns ao objetivo da pesquisa, realizou-se a seleção dos trabalhos por meio dos títulos, seus resumos e introduções para identificar aqueles que dialogam com o objetivo deste 
estudo e assim, estabelecer um diálogo em que se pudesse apontar os distanciamentos e aproximações com a proposta desse trabalho.

\section{Resultados e Discussão}

Em sua definição sobre os efeitos positivos dos conflitos McIntyre (2007) lembra que o conceito de solução de conflitos até meados do século XX, que era visto apenas pela sua eliminação, ampliou-se para compreender a gestão enquanto minimizadora dos aspectos negativos e maximizadora dos positivos, relevando o acordo construtivo entre as partes.

Para Bacal (2004) a visão positiva dos conflitos diz respeito ao aspecto questionador dos processos gerados por eles, como estímulo aos membros da organização para incrementar conhecimentos e habilidades, bem como contribuir para processos inovadores nas instituições.

Os conflitos são construtivos quando melhoram a qualidade das decisões, estimulam a criatividade e inovação e encorajam interesses e a curiosidade entre membros de equipes, fornecendo meios pelos quais os problemas podem ser manifestados, diminuindo tensões e fomentando um ambiente de autoavaliação e mudança (Bacal, 2004).

Assim, destaca McIntyre (2007), se ignorado, o conflito faz com que pessoas utilizem estilos de evitar ou de se acomodar diante de tais situações, permanecendo caladas - uma atitude que acaba significando uma perda para a organização. Logo, lembra Carvalhal et al. (2006), o gestor escolar deve avaliar cada situação conflituosa para averiguar suas causas e decidir se é necessária uma intervenção e qual abordagem é mais produtiva.

Os conflitos construtivos são os que têm o poder de exercer efeitos positivos para a escola. Hocker e Wilton (2006) sustentam que seus benefícios são vistos nos conflitos interpessoais que vão desde unir as pessoas contra um inimigo comum, alheio à instituição, promover coalizões que, bem dirigidas, fortalecem a escola estimulando inclusive a desenvolver novos fatos ou soluções até a enxergar os aspectos incompatíveis e irreconciliáveis, como mais tranquilos, menos dramáticos e importantes.

Quanto aos impactos negativos dos conflitos, Bacal (2004) alerta que a visão negativa sugere que conflito pode provocar reações distintas no âmbito das instituições. Ela diz respeito à noção de que as organizações são criadas para atingir objetivos e metas, com perfeita definição sobre tarefas, responsabilidades, autoridade e outras funções e que, nesta formação, poderão surgir processos de conflito.

De acordo com as ideias de Hocker e Wilton (2006), o resultado do conflito destrutivo é evidentemente negativo para instituição e normalmente apresenta as seguintes características:

- Os participantes ficam insatisfeitos com o ocorrido e pensam que perderam algo em consequência do conflito.

- Alguns fazem todo esforço para restringir as alternativas dos oponentes e obter vantagens pessoais ou de grupo à custa de opositores na empresa.

- Os participantes não se concentram na solução do problema, atacam as pessoas que deles divergem e ainda outros de seu próprio grupo.

- As partes envolvidas buscam causar danos umas às outras: não importam os resultados, desde que se contrarie a outra parte.

- Os funcionários tornam-se intratáveis, recusam-se a compartilhar informações e recursos e trabalham ativamente para minar os esforços dos oponentes.

- A produtividade tende a cair, os projetos atrasam e os bons funcionários se retiram da instituição por causa do ambiente tenso que o conflito deixa.

- Compromete de forma perceptível o prestígio da instituição e funcionários sendo percebido pela clientela. 
Na visão de Alan (2005), do ponto de vista tradicional, os conflitos no trabalho são vistos como algo perigoso, que deve ser eliminado o mais rapidamente possível. A fonte do conflito é identificada e removida usando a autoridade dos gestores. Os conflitos também são vistos como sinais de que o processo de administração não está funcionando bem, ou seja, não há bons chefes. A solução é alcançada com melhor planejamento, organização e controle.

As instituições têm situações conflitantes e que a responsabilidade dos chefes é aceitá-las e começar a manejá-las da melhor forma possível. No entanto, se forem permitidos demasiados conflitos, podem-se criar sérios problemas para a empresa (Alan, 2005).

Cabrera (2006) defende que, em contraste com as filosofias tradicionais e comportamentais, o conceito dos interrelacionistas aceita o potencial destrutivo dos conflitos, porém também acredita que, em algumas ocasiões, as instituições necessitam dos conflitos para estimular novas ideias e assegurar sua sobrevivência.

Hocker e Wilton (2006) lembram também a necessidade do indivíduo de ser valorizado, motivado a trabalhar exemplarmente na busca por uma meta, que, caso não seja atingida, faz com que ela própria sinta-se pressionado e desafiado a cumprir sua obrigação. Assim, existem vários sentimentos que acabam sendo desencadeados diante do surgimento de um conflito e que acabam gerando algum tipo de reação, conforme mostrado no Quadro 1.

Quadro 1: Mecanismos de defesa no ambiente organizacional.

\begin{tabular}{|c|l|}
\hline \multicolumn{2}{|c|}{ Mecanismos de Defesa mais Frequentes } \\
\hline Mecanismo de defesa & \multicolumn{1}{c|}{ Processo Psicológico } \\
\hline Escape & A pessoa se dedica a outras ocupações com vigor para minimizar o problema \\
\hline Impacto físico & Manifestam sintomas físicos como enfermidades, mal-estar, etc. \\
\hline Mudança & Redireciona emoções para pessoas ou coisas diferentes da fonte do problema. \\
\hline Englobamento & Imaginações para escapar da realidade e obter satisfações temporais. \\
\hline Oposição & Resistência inconsciente \\
\hline Justificativa & Tem postura e crenças indesejáveis com explicações "pseudológicas". \\
\hline Agressividade & Ao sentir injustiça ou incapacidade age com agressividade ao redor. \\
\hline Ausência & Separa-se do problema e rompe-se com a realidade demonstrando resignação. \\
\hline Renúncia & Abandona-se o local de trabalho com conflito depois de um enfrentamento. \\
\hline
\end{tabular}

Fonte: Hocker e Wilton (2006).

Logo, destacam os autores, os conflitos sobre objetivos obrigam as pessoas a tomarem decisões, embora o simples fato de agir para enfrentar esta tomada de decisões cria conflitos internos tanto em pessoas quanto em grupos.

Nesse sentido, destacam Carvalho e Oliveira (2007), um bom gestor não deve esperar pelo crescimento dos conflitos, mas enfrentá-los e ainda minimizá-los já nos primeiros indícios, para não exarcebarem a tranquilidade e evitar que saiam do controle, devido a um desgaste que possam provocar comprometendo o bom clima institucional, desviando esforços que devem ser dedicados ao cumprimento da missão da entidade e provocando incômodos que, às vezes, atingem limites intoleráveis tanto para o gestor como para os funcionários - motivo para procurar resolvê-lo o mais rápido possível.

E nesse universo, alerta Quinn (2003), dentre os diversos tipos de conflito, os interpessoais são os que mais alteram a dinâmica do ambiente de trabalho, pois geram sentimentos que causam instabilidade, desconforto, falta de cooperação e de confiança, tensão entre indivíduos ou grupos. Diversos sentimentos podem influenciar a tomada de ações prejudiciais ao trabalho e aos próprios indivíduos, ou até mesmo a ausência de ações, considerando-se que não agir já é tomar uma atitude e que a passividade pode gerar a mesma gama de transtornos.

De acordo com Koontz (2004), a complexidade dos conflitos trazidos pela interação promovida pela convivência diária, e muitas vezes extenuante, provoca desestabilidade entre os colaboradores no ambiente organizacional. Os conflitos são comuns a todas as instituições, a ponto de que, sem eles, elas se transformariam em empreendimentos atípicos e raros. Daí serem 
considerados como fenômenos comuns que exigem um leque de soluções para que não se tornem o pesadelo de qualquer administrador fugindo ao controle do gestor da instituição.

Em uma das muitas visões de Davis e Newstron (2006) enfatizam que o conflito desgasta porque compromete o bom clima institucional, desvia esforços que devem ser dedicados ao cumprimento da missão da entidade, provoca incômodo e, algumas vezes, atinge limites intoleráveis para o gestor e funcionários. Este é o motivo pelo qual se procura resolvê-lo o mais rapidamente possível.

Logo, definem Hocker e Wilton (2006), a solução efetiva de conflitos é uma arte adquirida por meio da experiência e do estudo permanente. Trata-se, segundo os autores, da habilidade de analisar as verdadeiras causas das desavenças e as formas adequadas de solucioná-las de maneira positiva para a instituição e para as partes envolvidas.

\subsection{Gestão de conflitos no ambiente escolar}

Segundo Albuquerque (2009), o concurso público de títulos e provas para Diretor escolar foi institucionalizado a partir de 1938, sendo mais tarde exigido que o candidato fosse professor efetivo do estado, com cinco anos de experiência docente. Essa normatização sofreu poucas alterações até a promulgação da LDB 5.692/71. Assim, passou a ser exigida a formação em Pedagogia com habilitação em Administração Escolar como requisito mínimo para inscrição no concurso para diretores embora, apesar dos investimentos em formação, os programas oferecidos não ajudam gestores a enfrentar os desafios diários.

Tais modalidades consistem em cursos, oficinas, seminários, palestras, cursos regulares de Pedagogia e em pósgraduação. O problema reside nos conteúdos tratados na maioria dessas modalidades - ou são muito teóricos, pouco úteis para as demandas do dia-a-dia, ou excessivamente técnicos, não contextualizando os problemas e conflitos da gestão (Albuquerque, 2009, p.03).

Grande parte dos gestores educacionais é proveniente do magistério e pelo destaque obtido como professores acabaram promovidos a diretores - o que acabou distorcendo a forma de encarar o papel para o qual não foram preparados. É possível ainda considerar que a formação acadêmica em Pedagogia não atende adequadamente à área de gestão educacional, deixando de enfocar aspectos críticos da gestão e fixando-se em detalhes de manutenção de rotinas administrativas (Albuquerque, 2009).

Garay Madariaga (2010) afirma haver uma interdependência entre comunicação e liderança. Para o autor, é preciso que a integridade do líder favoreça o processo comunicacional organizacional, estruturando um contexto de confiança, pois, embora não seja possível um ambiente escolar livre de conflitos, pelas diferenças e interesses individuais, ainda assim, se não bem gerenciado, ele leva ao caos e à anarquia, daí a necessidade de cortá-lo pela raiz.

Assim Dunham (2015) é enfático ao defender que o primeiro passo na gestão de conflitos é analisar a natureza e o tipo de conflito. Aqui, perguntas podem ser feitas e respostas podem vir da experiência do gestor e colaboradores. Já Griffin e Moorhead (2014) entendem que, uma vez que o administrador tenha uma compreensão geral do conflito, deve ser feita a seleção da resposta mais apropriada ao conflito. De onde sugerem cinco maneiras: acomodação, prevenção, competição, colaboração e compromisso.

- Acomodação: ocorre quando os objetivos são compatíveis, mas as interações não são consideradas importantes para a consecução geral dos objetivos. A dificuldade com o uso habitual dessa abordagem é a preservação de um relacionamento amigável às custas de avaliar criticamente os problemas e protestar contra os direitos pessoais.

- Evitar: as duas partes em um conflito tentam ignorar o problema e não fazem nada para resolver o desacordo. Evitar é muitas vezes ineficaz, pois a fonte real do desacordo não foi abordada. É provável que ele continue e a comunicação e cooperação sejam prejudicadas. 
- Concorrência: quando cada parte em conflito tenta maximizar seu próprio ganho e tem pouco interesse em entender a posição da outra parte e em chegar a uma solução que permita que ambas as partes alcancem seus objetivos. É uma tentativa de satisfazer as próprias necessidades às custas de outros - e que pode ser feito usando autoridade formal, ameaças físicas ou ignorando reivindicações da outra parte. O problema em se repetir essa abordagem é que ela gera hostilidade e ressentimento.

- Colaboração: as partes em conflito tentam satisfazer seus objetivos sem fazer concessões e, em vez disso, criam uma maneira de resolver suas diferenças que as deixam melhor. A intenção é encontrar soluções para a causa do conflito que sejam satisfatórias para ambas as partes, em vez de encontrar falhas ou atribuir culpas. Embora essa abordagem não seja apropriada para todas as situações, quando usada adequadamente tem efeito mais benéfico para os envolvidos.

- Compromisso: quando cada uma das partes se preocupa não apenas com o cumprimento da própria meta, mas também com a realização da outra parte e está disposta a participar de uma troca de dar e receber e fazer concessões até que uma solução razoável do conflito seja alcançada (Griffin e Moorhead, 2014).

Para Dunham (2015) antes das ações implementadas na resolução dos conflitos, é preciso preparar o terreno para uma negociação efetiva estabelecendo as bases. Deve haver iniciação onde o gestor escolar aumenta a possibilidade de negociação e inicia o processo com as condições corretas para que a negociação seja bem-sucedida numa logística pré-estabelecida.

Ao negociar, o diretor escolar deve discutir abertamente os interesses que não são claros, em vez das posições declaradas. Na gestão de conflitos, ele ou ela deve se concentrar em inventar opções para satisfazer o interesse. O diretor da escola não deve julgar ideias ou favorecer nenhuma das opções, mas, ao final da exposição dessas, deverão ser discutida para, ao final, todo parceiro ter certeza de que os outros cumprirão sua parte do acordo. Após essas discussões, quando a negociação estiver concluída, o grupo deverá então se preparar para implementar as decisões tomadas (Dunham, 2015).

Em uma pesquisa realizada numa escola estadual do Linhares-ES, acerca do clima organizacional e o gerenciamento dos conflitos na instituição, foi aplicado um questionário aos funcionários para levantamento de dados que, após serem colhidos, foram analisados e calculados estatisticamente. Dentre as perguntas feitas, duas em especial destacaram o clima e a eficiência da gestão escolar, considerada pelos entrevistados responsável direta pela administração dos conflitos:

Gráfico 1: Como você analisa o clima organizacional da escola?

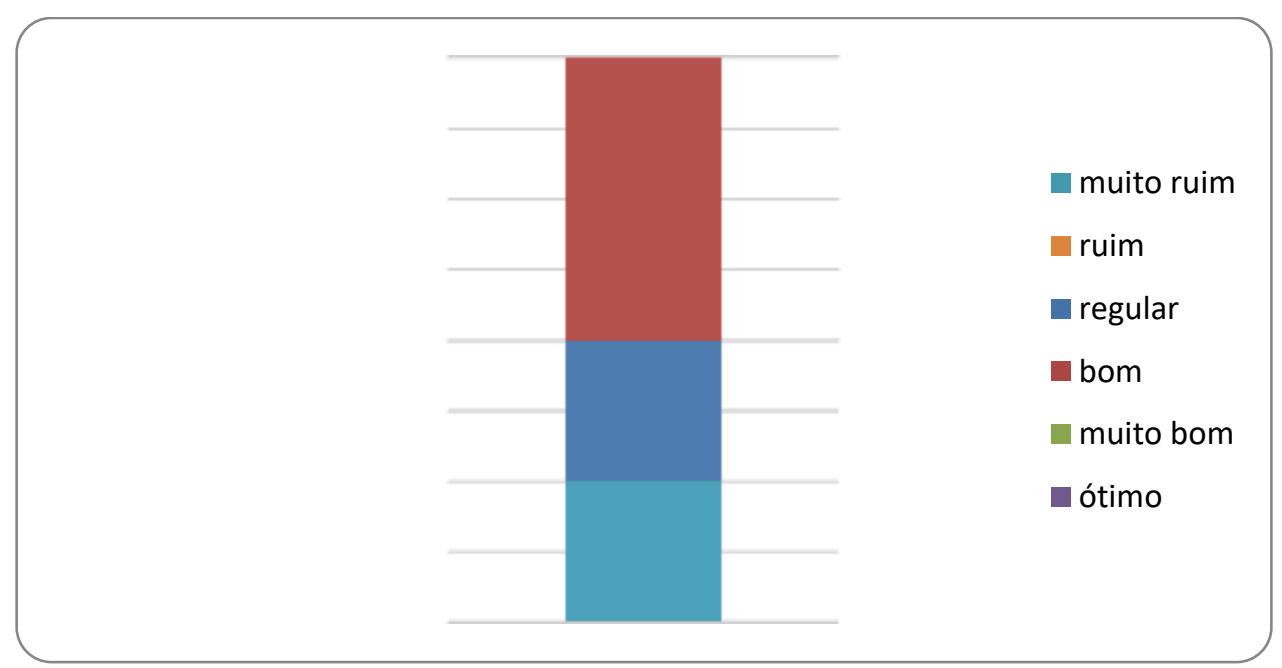

(10\%) Muito ruim. (5\%) Ruim. (20\%) Regular. (40\%) Bom. (20\%) Muito bom. (5\%) Ótimo.

Obs. A boa avaliação em relação ao clima organizacional pode ser atribuído a uma boa interação social entre os fatores humanos e a consequente otimização dos serviços de atendimento a pais, professores e alunos de forma a colaborar para a eficiência dos serviços prestados dentro do processo de ensino e aprendizagem ofertados. Fonte: Autores (2021). 
Em outra situação, dessa vez para avaliação da eficiência da gestão da escola, questionou-se:

Gráfico 2: Como você avalia o trabalho realizado pela gestão escolar na administração de conflitos?

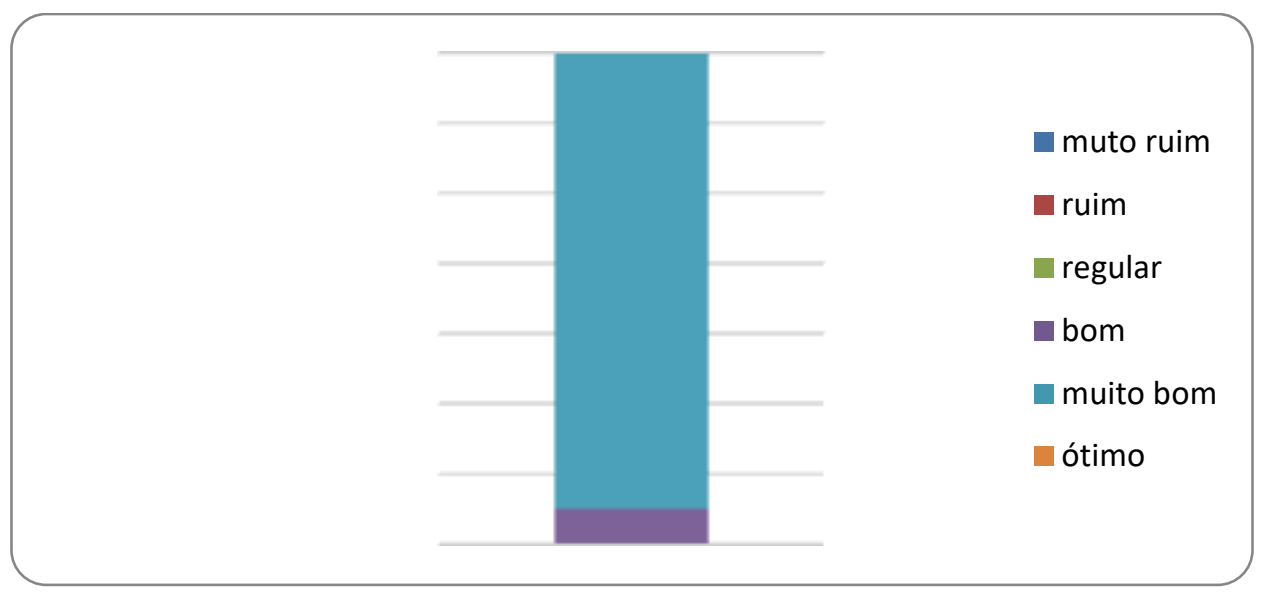

(0\%) Muito ruim. (0\%) Ruim. (0\%) Regular. (5\%) Bom. (70\%) Muito bom. (25\%) ótimo

Obs. Nesse caso, a satisfação com o atendimento da direção da escola também está associado aqui à segmentação do setor que foi feita para proporcionar um melhor atendimento ao professor/aluno. Esse processo de segmentação oferece uma gestão mais apta a desenvolver produtos e serviços mais aprimorados aos mais diferenciados alunos, usando a qualificação contínua de seus colaboradores como um recurso de vital. Fonte: Autor (2021).

O exercício da gestão escolar de escolas públicas não é tarefa das mais fáceis no Brasil, pois, são profissionais que trabalham aproximadamente dez horas por dia com prioridades cotidianas na agenda que vão de cuidar da infraestrutura, conferir merenda, vigiar o comportamento dos alunos, atender os pais, receber crianças, participar de reuniões, providenciar material, etc. Sobra pouco tempo para conversar com professores, prestar atenção nas aulas e buscar melhoria do ensino, meta essencial da escola (Chrispino, 2007).

O gerenciamento de conflitos é uma aptidão social natural para induzir os outros a respostas desejáveis. Dessa forma, o papel de um gestor comprometido com o desenvolvimento de seus subordinados e da organização é fundamental para a resolução de conflitos. Isso porque em grande parte das vezes a figura do gestor está envolvida em razão da posição que este ocupa - que determina conflitos relacionados à hierarquia, às tarefas e às relações de poder - e porque, muitas das vezes, ele é chamado pelos próprios atores envolvidos no conflito a contorná-lo e resolvê-lo (Goleman, 2006).

Gráfico 3: Elementos preponderantes no gerenciamento de conflitos.

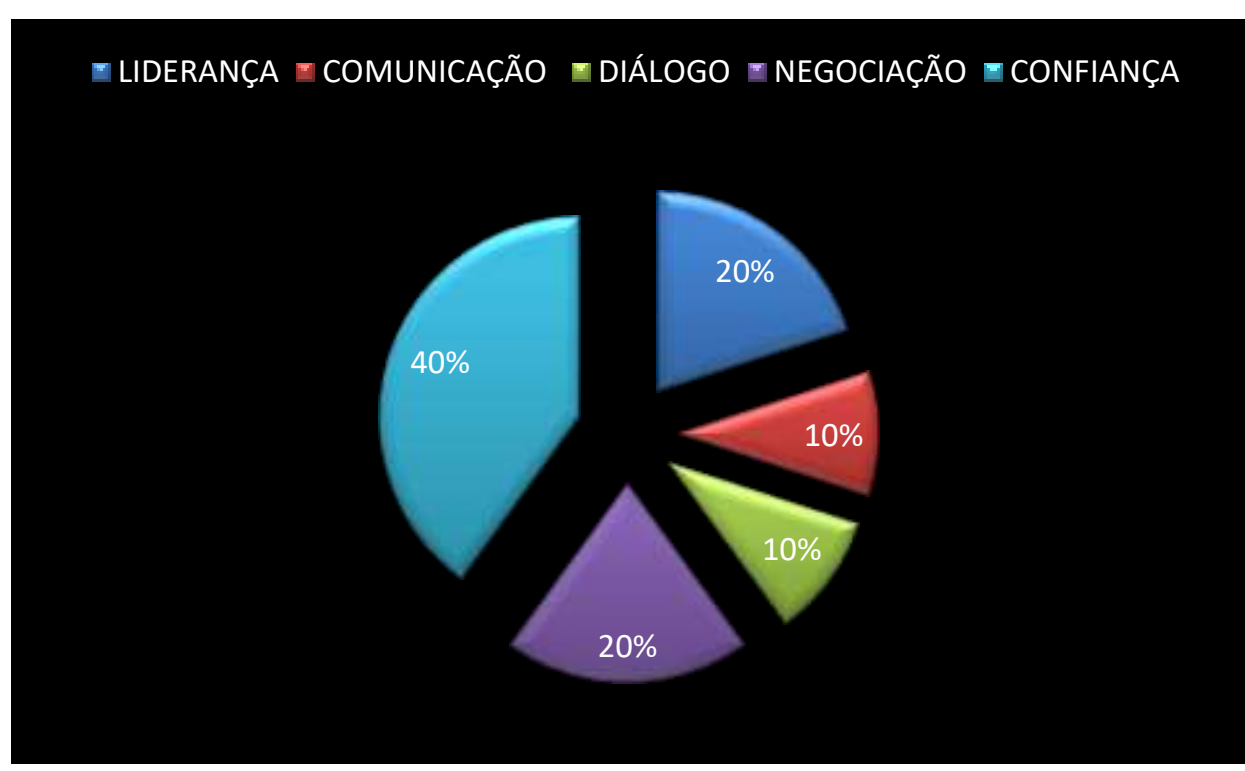

Adaptado de Goleman (2006). 
Goleman (2006) destaca ainda que o diretor escolar deve ser gestor da dinâmica social, mobilizador e orquestrador de atores e articulador da diversidade para dar unidade e consistência na construção do ambiente educacional e promover a formação dos alunos.

A atuação da liderança deve ser pautada ainda pelo diálogo e negociação de forma a sempre buscar construir relações de confiança que permitiam atribuir significado à ação dos liderados, faz parte de seu papel nessa engrenagem, administrar mais as relações que se estabelecem no espaço de atuação profissional do que a infraestrutura material. Logo seu principal desafio é fazer com que as pessoas remem na mesma direção, que compartilhem princípios ou fundamentos para orientar e estimular a participação de todos (Albuquerque, 2009).

Para Lück (2009) o diretor escolar deve ser um gestor da dinâmica social, um mobilizador e orquestrador de atores, um articulador da diversidade para dar unidade e consistência na construção do ambiente educacional e promoção segura da formação de seus alunos, chamado a admitir seu papel político frente aos desafios exigidos pelo seu cargo.

O conflito pode ser prejudicial e valioso e por isso deve ser gerenciado de tal maneira que traga mais ganhos do que danos às escolas. Uma forma de conseguir isso é levar as pessoas afetadas ou envolvidas a um diálogo em que cada uma terá uma chance justa de expressar seu ponto de vista através do diretor da escola que deve agir como mediador de conflitos e desempenhar o papel de um juiz, assegurando que a racionalidade e a objetividade reinem no diálogo, para que as partes em conflito cheguem a um consenso sobre a questão das preocupações (Okotoni, 2002).

Na visão de Dunham (2015) o conflito nas escolas torna-se prejudicial se os grupos continuarem a insistir nas suas personalidades ou no que as dividiu, e não em questões e fatos. Assim as reuniões da equipe são uma das instituições mais valiosas para garantir o melhor funcionamento da escola. Além de ser um fórum no qual membros da equipe trocam ideias, é também um lugar onde o espírito de unidade deve ser desenvolvido e onde as opiniões de todos podem ser adequadamente orientadas para as ideias que a escola pretende sustentar.

Ao intermediar uma situação de conflito o diretor escolar deve discutir abertamente os interesses pouco claros em vez das posições declaradas. Assim ele se concentra em criar opções que satisfaçam os interesses sem julgar ideias ou favorecer qualquer uma das opções. Somente depois que os parceiros listarem suas opções, elas serão discutidas. Ao final, cada parte deve estar confiante de que o outro cumprirá o que foi acordado (Dunham, 2015).

Nas competências emocionais de um gestor escolar, um novo conceito de gestão emocional foi ser estabelecido para administrá-lo, para que o indivíduo tenha capacidade de gerir as próprias emoções e as emoções da equipe, que Goleman (2006) dividiu em:

- Autopercepção: saber o que estamos sentindo num determinado momento e usar as preferências que guiam a tomada de decisão; fazer uma avaliação precisa e realista das próprias capacidades e possuir uma sensação bem fundamentada de autoconfiança.

- Auto-regulamentação: Lidar com as próprias emoções de forma que facilitem a tarefa que temos pela frente, em vez de interferir com ela; ser consciencioso e adiar a recompensa para perseguir as metas; recuperarmo-nos bem de aflições emocionais.

- Motivação: usar nossas preferências mais profundas para nos impulsionar e guiar na direção das metas a fim de nos ajudar a ter iniciativa e sermos altamente eficazes, e a perseverarmos diante de reveses e frustrações.

- Empatia: pressentir o que as pessoas estão sentindo sendo capaz de assumir sua perspectiva e cultivar o rapport e a sintonia com ampla diversidade de pessoas. 
- Habilidades sociais: Lidar bem com as emoções nos relacionamentos e com precisão situações sociais e redes; interagir com facilidade; utilizar as habilidades para liderar, negociar e solucionar divergências, e para a cooperação e o trabalho em equipe.

Gráfico 4: Considerações sobre competências emocionais mais importantes de um gestor.

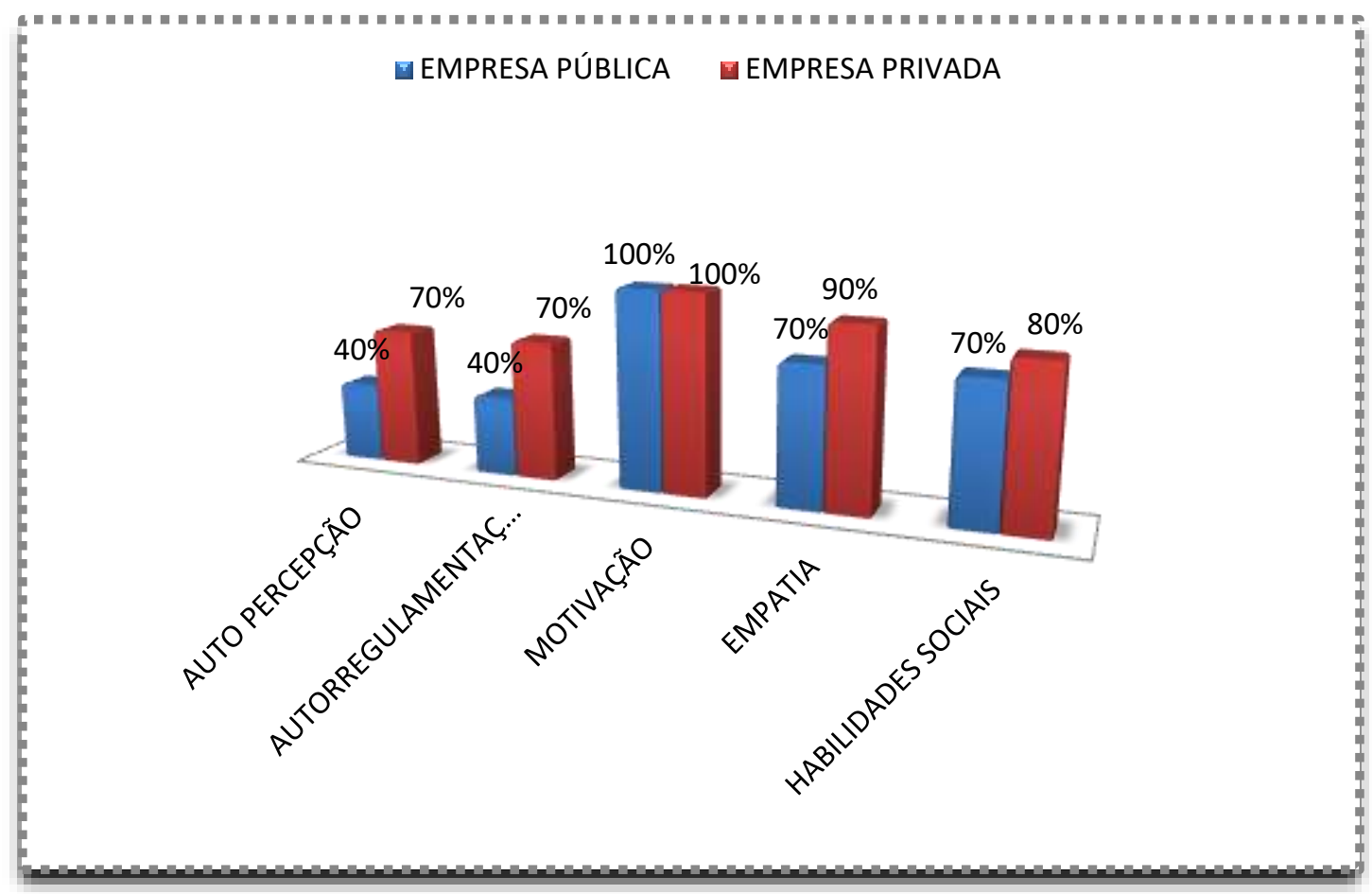

Adaptado de Goleman (2006).

Para Iwuagwu (2011), nas reuniões de equipe, as diferenças dos professores que podem resultar em conflito são expostas e discutidas para encontrar solução para o conflito. Assim, através da comunicação já se começa a criar uma atmosfera para uma comunicação eficaz, de forma que haja uma boa rede de comunicação vertical e horizontal no sistema escolar.

Palavras claras e precisas devem ser usadas, em canais apropriados que sejam mais apropriados para transmitir mensagens, a fim de evitar informações erradas e mal-entendidos que levem a conflitos, da mesma forma que professores e alunos devem ser também esclarecidos e educados sobre seu código de conduta para que cada um entenda seus limites e mais conflitos sejam evitados (Iwuagwu, 2011).

\section{Conclusão}

Normalmente os problemas mais difíceis de serem solucionados numa escola ou em qualquer outra organização, são os relacionados a funcionários. Os de trabalho são focados em serviços, procedimentos, calendários, turnos, tempos, salários, recompensas, punições, custos, etc. Os problemas referentes às pessoas envolvem emoções, expectativas, necessidades, motivação e todos os outros aspectos intangíveis associados ao comportamento humano.

Os problemas que envolvem conflitos de pessoas que trabalham em conjunto geralmente são conhecidos porque os funcionários não demoram em se queixar. A intervenção para solucioná-los é uma consulta apropriada, porém chegar ao âmago da questão, ou seja, ao motivo real do problema, pode levar tempo porque isso depende do número de pessoas envolvidas, de suas emoções e, provavelmente, de seus desacordos acerca dos fatos. 
Quanto ao objetivo geral, foi possível alcançá-lo de forma eficiente, pois houve o devido aprofundamento na natureza dos conflitos que podem ocorrer no ambiente escolar e, consequentemente, os respectivos impactos, positivos e negativos que essas divergências podem ocasionar no clima interno e na estrutura pedagógica da escola.

A metodologia utilizada foi suficiente para realização dos devidos procedimentos e demonstração de como a administração de conflitos humanos no ambiente escolar está longe de ser uma tarefa fácil para nossos gestores, mesmo com o amplo leque de soluções para ser resolvida. Assim, é preciso lançar mão de todo conhecimento possível, além da experiência e diálogo quase que diário para administrar esse processo que fazem parte do dia-a-dia de qualquer ambiente organizacional.

Quanto à bibliografia utilizada, a mesma correspondeu às expectativas no momento em que foi essencial para resposta das diversas formas de se gerenciar e eliminar atritos dentro do ambiente escolar, e não apenas desviá-los no processo de conflitos e na resolução e entendimento dos pares envolvidos, principalmente, além dos benefícios que tanto a escola quanto seus colaboradores se beneficiarão com a resolução dessas pendências.

Após análise e leitura do material deste estudo, assim como as referências utilizadas para sua construção foi possível perceber a necessidade de se ter o máximo de cautela nas decisões tomadas no âmbito escolar no que tange à resolução de conflitos pessoais dos funcionários no ambiente organizacional, uma vez que o sucesso da escola depende de forma direta do clima harmonioso e do relacionamento de parceria entre os membros de sua equipe.

\section{Referências}

Alan, C. (2005). Soluções de conflitos interpessoais. Revista Técnica. Editora Trillas, México.

Albuquerque, N. S. (2009). Gestor escolar - um mediador de conflitos. http://www.com.br/gestao/arquivosfile/Artigocientificopdf. 2009.

Bacal, R. (2004). Conflitos Organizacionais: o bom, o mal e o feio. In: The Journal for Quality \& Participation. EUA.

Cabrera, M. (2006). A comunicação e a administração de conflitos. Editora Percan, Lima.

Carvalhal, E, André Neto, A, \& Andrade, G. (2006). Negociação e administração de conflitos. FGV.

Carvalho, C. A, \& Vieira, M. M. F (2007). O poder nas organizações. Thomson Learning.

Conforto, E. C, Amaral, D. C, \& Silva, S. L. (2011). Roteiro para Revisão Bibliográfica Sistemática: Aplicação no Desenvolvimento de Produtos e Gerenciamento de Projetos. Congresso Brasileiro de Gestão de Desenvolvimento de Produto - CBGDP, 1(12).

Chrispino, A. (2007). Gestão do conflito escolar: da classificação dos conflitos aos modelos de mediação. Ensaio: avaliação das políticas públicas Educacionais, Rio de Janeiro, 15(54).

Davis, K, \& Newstron, J. E. (2006). O comportamento humano no trabalho. Comportamento organizacional. Editora MCgraw. México.

Brasil. Lei $\mathrm{n}^{\circ}$ 5.692, de 11 de agosto de 1971. Fixa Diretrizes e Bases para o ensino de $1^{\circ}$ e $2^{\circ}$ graus, e dá outras providências. www.planalto.gov.br/ccivil_03/Leis/L5692.htm

Dunham, J. (2015). Desenvolvimento de uma gestão escolar eficaz. Routledge.

Garay Madariaga, M. (2010). Comunicação e liderança: sem comunicação não há lider. Cuadernos del Centro de Estudios en Diseño y Comunicación, Ensaio. 33(61-72).

Goleman. (2006). Trabalhando com a inteligência emocional. Objetiva.

Griffin, R. W, \& Moorhead, G. (2014). Comportamento Organizacional: Gerenciando Pessoas e Organização. 8th ed. Houghton Mifflin Company, Boston, New York.

Hocker, J, Wilton L. (2006). Conflitos interpessoais. Editora C. Brown. Califórnia.

Iwuagwu, B. O. (2011). Gerenciamento de conflitos relacionados à escola. An Unpublished Ph.D. Seminar work submitted to the department of Educational Foundations and Management, Faculty of Education, Ambrose University, Ekpoma.

Koontz, H. (2004). Administração do capital humano: uma perspectiva global. Editora Mcgraw, Califórnia.

Lück, H. (2009). Dimensões da Gestão Escolar e suas competências. Curitiba: Editora Positivo.

Mcintyre, S. E. (2007). Como as pessoas gerem o conflito nas organizações: estratégias individuais negociais. Análise Psicológica. Lisboa, 25(2), 295-305. 
Research, Society and Development, v. 10, n. 17, e200101724717, 2021

(CC BY 4.0) | ISSN 2525-3409 | DOI: http://dx.doi.org/10.33448/rsd-v10i17.24717

Okotoni, C. A. (2002). Gestão de Conflitos em Escolas Secundárias no Estado de Osun. M.A. thesis, Obafemi Awolowo University, Ile-Ife.

Quinn, R. E et al. (2003). Competências Gerenciais: princípios e aplicações. Elsevier. 